\title{
SSynthesis
}

International Scientific Conference of IT and Business-Related Research

\section{AERODINAMIČKI KOEFICIJENT SILE OTPORA VAZDUHA PRI SIMETRIČNOM OPSTRUJAVANJU LETELICE}

\section{THE AERODYNAMIC COEFFICIENT OF AIR RESISTANCE FORCE \\ IN A SYMMETRIC AIRCRAFT FLOW}

\author{
Dušan Regodić ${ }^{1}$, Damir Jerković ${ }^{3}$, Aleksandar Jevremović ${ }^{1}$, Nenad Ristić ${ }^{1}$, Marija Matotek $^{2}$ \\ ${ }^{1}$ Univerzitet Sinergija, Bijeljina, Republika Srpska \\ ${ }^{2}$ Univerzitet Singidunum, Beograd, Srbija \\ ${ }^{3}$ Vojna Akademija, Beograd, Srbija
}

\section{Apstrakt:}

Simetrično opstrujavanje letelice nastupa pri napadnom uglu $\sigma=0^{0}$. U radu je primenjen poluempirijski metod proračuna aerodinamičkog koeficijenta Cx i njegovih komponenata (AERODR). Osnovni sistem jednačina rešava se odgovarajućim matematičkim postupkom i u svom konačnom obliku daje međusobni odnos komponenata aksijalnog aerodinamičkog koeficijenata za osnosimetrično opstrujavanje. Rešenjem autori smanjuju vrednost Cx (McCoy, 1999) do pet procenata, tako da vrednosti aerodinamičkog koeficijenta $\mathrm{Cx}$ ne prelaze 0.4 . Rezultati dobijeni proračunom u skladu su sa postavljenim pretpostavkama i u okviru očekivanih vrednosti.

\section{Ključne reči:}

telo letelice, aerodinamički koeficijent, sila otpora vazduha, simetrično opstrujavanje.

\section{UVOD}

Klasična osnosimetrična letelica predstavlja rotaciono kruto telo definisanih konstruktivnih parametara. Ova vrsta letelice nema dodatne aerodinamičke površine i dodatni energetski resurs tokom kretanja u vidu reaktivne sile i svoju stabilnost tokom leta obezbeđuje ugaonom brzinom oko glavne uzdužne ose (dinamičkom i žiroskopskom stabilnošću).

Kretanje ostvaruje u atmosferi od napuštanja „usta“ cevi oružja - oruđa sa definisanom polaznom brzinom i polaznim uglom u odnosu na mesto lansiranja. Oblik klasičnog osnosimetrične letelice je tokom godina evoluirao u skladu sa tehničkotehnološkim razvojem društva i naučno-tehničkih disciplina. Savremeni klasični osnosimetrične letelice se sastoji od prednjeg dela, tela (srednjeg dela) i zadnjeg dela. Prednji deo najčešće je oživalnog oblika (luk kružnice rotiran oko odabrane ose) ili kombinacije oživala i konusa. Srednji deo je telo letelice cilindričnog oblika na kom se izdvajaju centrirajući prsten i vodeći prsten. Centrirajući prsten predstavlja prednji deo cilindričnog tela delimično većeg prečnika i precizno obrađene površine. Vodeći prsten je od legure bakra i nalazi se na zadnjem delu cilindričnog tela. Zadnji deo letelice je oblika zarubljenog konusa. Dno klasične osnosimetrične letelice je najčešće ravno, i svojom površinom se suprotstavlja dejstvu pritiska barutnih gasova, koji sagorevanjem deluju na dno i obezbeđuju letelici potrebnu početnu brzinu (Ul-Haque \& Umar, 2005).

\section{Abstract:}

The symmetrical appearance of a missile at the angle of attack is $\sigma=0^{0}$. The paper uses semi-empirical method of calculating the aerodynamic coefficient $\mathrm{Cx}$ and its components (AERODR). The basic equation system is solved using the appropriate mathematical procedure and it shows mutual relationship of axial components of aerodynamic coefficients for symmetric airflow over in its final form.

The authors reduced the value of $\mathrm{Cx}$ to five per cent, so that the values of the aerodynamic coefficient $\mathrm{Cx}$ do not exceed 0.4 . The results obtained are in accordance with the given assumptions and around the expected values.

\section{Key words:}

body aircraft, aerodynamic coefficient, air resistance force, symmetrical airflow.

Prilikom kretanja u atmosferi kao rezultat interakcije osnosimetrične letelice i atmosfere javlaja se ukupna aerodinamička sila i moment (Regodić, 2006). Predmet analize ovog rada je korekcija vrednosti aerodinamičkog koeficijenta aksijalne sile (Regodić, 2003).

\section{SISTEM JEDNAČINA I ANALITIČKO REŠENJE}

Ukupni aerodinamički koeficijent otpora aksijalne sile po metodi AERODR iznosi:

$\mathrm{C}_{\mathrm{X}}=\mathrm{C}_{\mathrm{X} 1}+\mathrm{C}_{\mathrm{XSF}}+\mathrm{C}_{\mathrm{XVP}}+\mathrm{C}_{\mathrm{X} 3}+\mathrm{C}_{\mathrm{XD}}$

gde su:

$\mathrm{C}_{\mathrm{x} 1}$ - koeficijent talasnog otpora vrha letelice,

$\mathrm{C}_{\mathrm{XSF}}-$ koeficijent otpora trenja,

$\mathrm{C}_{\mathrm{XVP}}$ - koeficijent otpora vodećeg prstena,

$\mathrm{C}_{\mathrm{X} 3}$ - koeficijent talasnog otpora zadnjeg konusa i

$\mathrm{C}_{\mathrm{XD}}$ - koeficijent otpora dna letelice.

Koeficijent talasnog otpora vrha letelice iznosi:

$$
C_{X 1}=\frac{f\left(\beta \sqrt{M_{\infty}^{2}-1}, \beta\right)}{\left(M_{\infty}^{2}-1\right)}, \text { odnosno }
$$


$C_{X 1}=\frac{\left(B_{1}-B_{2} \beta^{2}\right) \cdot\left(\beta \sqrt{M_{\infty}^{2}-1}\right)^{\left(\mathrm{B}_{3}+B_{4} \beta\right)}}{\left(M_{\infty}^{2}-1\right)}$

$\mathrm{C}_{\mathrm{X} 1}=\mathrm{C}_{\mathrm{X} 1 \mathrm{~V}}+\mathrm{C}_{\mathrm{xz}}$

pri čemu je:

$C_{X 1 V}=\frac{\left(B_{1}-B_{2} \beta^{2}\right) \cdot\left(\beta \sqrt{M_{\infty}^{2}-1}\right)^{\left(B_{3}+B_{4} \beta\right)}}{\left(M_{\infty}^{2}-1\right)}$

$\beta=\frac{d-d_{M}}{2 L_{N}}-$ nagib koničnog vrha,

$\mathrm{B}_{1}=0.6256-0.5313\left(\mathrm{R}_{\mathrm{T}} / \mathrm{R}\right)+0.595\left(\mathrm{R}_{\mathrm{T}} / \mathrm{R}\right)^{2}-$ konstanta,

$\mathrm{B}_{2}=0.0796+0.0779\left(\mathrm{R}_{\mathrm{T}} / \mathrm{R}\right)-$ konstanta,

$\mathrm{B}_{3}=1.587+0.049\left(\mathrm{R}_{\mathrm{T}} / \mathrm{R}\right)-$ konstanta,

$\mathrm{B}_{4}=0.1122+0.1658\left(\mathrm{R}_{\mathrm{T}} / \mathrm{R}\right)-$ konstanta,

$R F=\sqrt{M_{\infty}^{2}-1}-$ konstanta,

$Z=\frac{1}{M_{\infty}^{2}-1}-$ konstanta,

$\mathrm{MC}=1+0.9567 \beta^{1.85}-$ kritični Mahov broj.

$\mathrm{Za} \mathrm{M}_{\propto}<\mathrm{M}_{\mathrm{C}}$ uvodi se oznaka $Z E=R F=\sqrt{M_{\infty}^{2}-1} \mathrm{i}$

sledi da je $C_{X I}=\frac{M_{\infty}^{2}-1}{2.4 M_{\infty}^{2}}$.

$\mathrm{Za}_{\propto}<1$ uvodi se oznaka

$\mathrm{P}_{\mathrm{TP}}=\left(1+2 \mathrm{M}^{2}{ }_{\propto}\right)^{3.5}$.

Za nadzvučno strujanje $\mathrm{M}_{\propto}>1$, pa je vrednost

$$
\begin{aligned}
& \mathrm{P}_{\mathrm{TP}}=\left(1+2 \mathrm{M}_{\infty}^{2}\right)^{3.5}\left(\frac{6}{7 \mathrm{M}_{\infty}^{2}-1}\right)^{2.5} \\
& C_{X 1 P}=\frac{1.22 \cdot\left(P_{T P}-1\right) \cdot d_{M}^{2}}{M_{\infty}^{2}} .
\end{aligned}
$$

Za podzvučno strujanje $\mathrm{M}<0.91$ vrednost koeficijenta $\mathrm{C}_{\mathrm{xz}}=0$, a za nadzvučno strujanje pri $\mathrm{M}>1.41$ vrednost koeficijenta $\mathrm{C}_{\mathrm{XZ}}=0.85 \mathrm{C}_{\mathrm{x} 1 \mathrm{P}}$. $\mathrm{U}$ intervalu $0.91<\mathrm{M}<1.4$

$$
\mathrm{C}_{\mathrm{XZ}}=\left(0.245+2.88 \mathrm{C}_{\mathrm{XI}}\right) \mathrm{C}_{\mathrm{x} \mathrm{P}} \text {. }
$$

Na slici 1. prikazane su dimenzije vrha letelice.

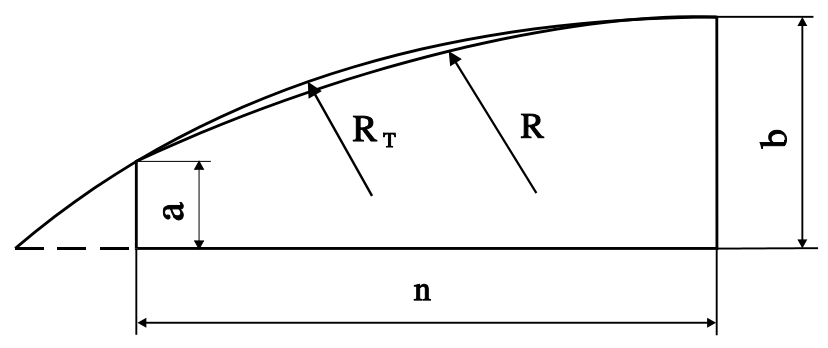

Slika 1. Dimenzije vrha letelice
Radijus tangentnog oživala je

$\mathrm{R}_{\mathrm{T}}=\sqrt{\mathrm{c}^{2}+\frac{\mathrm{c}^{2} \cdot \mathrm{n}^{2}}{(b-a)^{2}}}$,

pri čemu su:

$\mathrm{n}$ - dužina oživala,

a i b - poluprečnici baze oživala,

$\mathrm{c}=\sqrt{\frac{1}{4}(\mathrm{~b}-\mathrm{a})^{2}+\mathrm{n}^{2}} \mathrm{i}$

$\mathrm{R}$ - stvarni radijus, za konus $\mathrm{R}=\propto$.

Na osnovu dimenzija radijusa tangentnog oživala i stvarnog oživala dobija se:

$\mathrm{RT} / \mathrm{R}=0$ - za konus,

$\mathrm{RT} / \mathrm{R}=1-$ za tangentni ožival, $\mathrm{i}$

$\mathrm{RT} / \mathrm{R}=0 \div 1-$ za varijacije sekantnog oživala.

Vrh projektila oblika kupe prikazan je na slici 2.

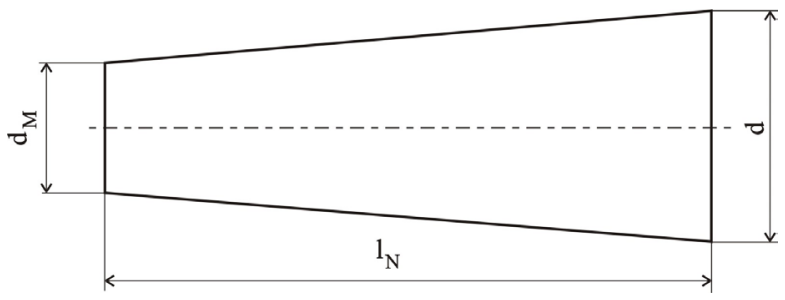

Slika 2. Geometrija koničnog vrha letelice

Jednačina koeficijenta otpora za konični vrh $\mathrm{C}_{\mathrm{x} 1}$ koriguje se sa koeficijentom promene pritiska $\mathrm{C}_{\mathrm{PS}}$.

$$
\mathrm{C}_{\mathrm{X} 1}=\frac{\left(\mathrm{C}_{1}-\mathrm{C}_{2} \beta^{2}\right)}{\mathrm{M}_{\infty}^{2}-1}\left[\beta \sqrt{\mathrm{M}_{\infty}^{2}-1}\right]^{\left(\mathrm{C}_{3}+\mathrm{C}_{4} \beta\right)}+\frac{\pi}{4} \mathrm{~d}_{\mathrm{M}}^{2} \mathrm{C}_{\mathrm{PS}},
$$

pri čemu je po Moru:

$$
\begin{aligned}
& \mathrm{C}_{\mathrm{PS}}=\frac{2}{\chi \mathrm{M}_{\infty}^{2}}\left[0.9\left(\frac{(\chi+1) \mathrm{M}}{2}\right)^{\frac{\chi}{\chi-1}}\left(\frac{\chi+1}{2 \chi \mathrm{M}_{\infty}^{2}-(\chi-1)}\right)^{\frac{\chi}{\chi-1}-1}-1\right], \\
& \mathrm{C}_{\mathrm{X} 1}=\frac{\pi}{4} \mathrm{C}_{\mathrm{PS}}=1.122\left[\left(1.2 \mathrm{M}_{\infty}^{2}\right)^{3.5}\left(\frac{6}{7 \mathrm{M}_{\infty}^{2}-1}\right)^{2.5}\right],
\end{aligned}
$$

$\mathrm{K}$ - koeficijent korekcije zbog promene pritiska na površini letelice. Kartes i Stein su predložili $\mathrm{K}=0.9$. Dikinson je dao eksperimentalne rezultate za konični oživalni vrh pri supersoničnim brzinama $\mathrm{K}=0.75$. Za vitke oživale Kol, Solomon i Vilmarth su predložili:

$$
\frac{\mathrm{C}_{\mathrm{X} 1}}{\beta^{3}}+\ln \beta=\mathrm{f}\left[\frac{\mathrm{M}_{\infty}^{2}-1}{(\chi+1) \mathrm{M}_{\infty}^{2} \beta^{2}}\right] .
$$

Proračunate vrednosti su približno jednake eksperimentalnim. Von Karman je za dvodimenzionalnu transoniku vitkih tela dao pojednoStavljenu formulu:

$$
\mathrm{C}_{\mathrm{X} 1}=\sqrt[3]{(\chi+1) \mathrm{M}_{\infty}^{2}}=\mathrm{f}\left\{\frac{\mathrm{M}_{\infty}^{2}-1}{\left[(\chi+1) \mathrm{M}_{\infty}^{2} \beta\right]^{\frac{2}{3}}}\right\} .
$$


Za osnosimetrični trodimenzionalni oblik za transoniku je:

$$
\mathrm{C}_{\mathrm{X} 1}=\mathrm{F}(\beta)+\mathrm{f}\left[\frac{\beta\left(\mathrm{M}_{\infty}^{2}-1\right)}{(\chi+1) \mathrm{M}_{\infty}^{2}}\right]
$$

$\mathrm{za} \mathrm{M}_{\infty}>\mathrm{M}_{\mathrm{c}}$

gde je $M_{c}=\frac{1}{\sqrt{1+0.552 \sqrt[5]{\beta^{4}}}}$

\subsection{KOEFICIJENT TALASNOG OTPORA ZADNJEG KONUSA}

Pri supersoničnom opstrujavanju koničnog dna letelice, za male vrednosti ugla zadnjeg konusa $\theta_{\mathrm{d}}$ predlaže se jednačina otpora zadnjeg konusa:

$\mathrm{C}_{\mathrm{X}^{*}}=\frac{4 \mathrm{Z}_{1} \tan \theta_{\mathrm{d}}}{\lambda}\left[\left(1-\mathrm{e}^{-\lambda \mathrm{L}_{\mathrm{BT}}}\right)+2 \tan \theta_{\mathrm{d}}\left(\mathrm{e}^{-\lambda \mathrm{L}_{\mathrm{BT}}}\left(\mathrm{L}_{\mathrm{BT}}+\frac{1}{\lambda}\right)-\frac{1}{\lambda}\right)\right]$

pri čemu su:

$\mathrm{C}_{\mathrm{X}^{*}}-$ proračunata vrednost talasnog otpora zadnjeg konusa,

$\theta_{\mathrm{d}}$ - ugao zadnjeg konusa (negativna vrednost za konični deo),

LBT- dužina zadnjeg konusa u kalibrima,

Z1- odgovarajući koeficijent promene pritiska za PrandlMajerovu ekspanziju,

$\lambda$ - koeficijent popravke pritiska zadnjeg konusa.

Koeficijenti $Z_{1}$ i $\lambda$ dobijeni su metodom karakteristika za letelice čiji je zadnji deo oblika konusa:

$$
\mathrm{Z}_{1}=\mathrm{Z}_{2} \mathrm{e}^{-\sqrt{\frac{2}{\mathrm{M}_{\infty}^{2} \mathrm{~L}_{\mathrm{CLL}}}}}+\frac{2 \tan \theta_{\mathrm{d}}}{\sqrt{\mathrm{M}_{\infty}^{2}-1}}-\frac{\left[(\chi+1) \mathrm{M}_{\infty}^{2}-4\left(\mathrm{M}_{\infty}^{2}-1\right)\right] \tan ^{2} \theta_{\mathrm{d}}}{2\left(\mathrm{M}_{\infty}^{2}-1\right)},
$$

pri čemu je prednji korekcioni faktor otpora zadnjeg konusa za supersonične brzine:

$$
\begin{aligned}
& \mathrm{Z}_{2}=\left[1-\frac{3\left(\frac{\mathrm{R}_{\mathrm{T}}}{\mathrm{R}}\right)}{5 \mathrm{M}_{\infty}}\right]\left[\frac{5 \beta}{6 \sqrt{\mathrm{M}_{\infty}^{2}-1}}+\left(\frac{\beta}{2}\right)^{2}-\frac{0.7435}{\mathrm{M}_{\infty}^{2}}\left(\beta \cdot \mathrm{M}_{\infty}\right)^{1.6}\right], \\
& \mathrm{k}=\frac{0.85}{\sqrt{\mathrm{M}_{\infty}^{2}-1}} .
\end{aligned}
$$

\subsection{AERODINAMIČKI KOEFICIJENT OTPORA TRENJA}

Koeficijent otpora trenja CXSF može se izračunati na osnovu

$$
\mathrm{C}_{\mathrm{XSF}}=\frac{\mathrm{C}_{\mathrm{XSFL}} \cdot \mathrm{S}_{\mathrm{WN}}+\mathrm{C}_{\mathrm{XSFT}} \cdot \mathrm{S}_{\mathrm{WCYL}}}{\mathrm{S}_{\mathrm{W}}},
$$
$\mathrm{C}_{\mathrm{FL}}=\mathrm{C}_{\mathrm{FT}}$

pri čemu je za turbolentni granični sloj $(\mathrm{IBLC}=2)$ vrednost

$$
\mathrm{C}_{\mathrm{XSFT}}=\frac{4}{\pi} \mathrm{C}_{\mathrm{FL}} \mathrm{S}_{\mathrm{W}} \text {. }
$$

Za laminarni granični sloj po Blasiusu $(\mathrm{IBLC}=1)$ vrednost

$$
\mathrm{C}_{\mathrm{FLT}}=\frac{1.328}{\sqrt{\mathrm{Re}}}\left(1+0.12 \mathrm{M}_{\infty}^{2}\right)^{-0.12}
$$

Ukupna opstrujavana površina je:

$\mathrm{S}_{\mathrm{V}}=\mathrm{S}_{\mathrm{VV}}+\mathrm{S}_{\mathrm{VCIL}}$

pri čemu je površina cilindričnog dela

$\mathrm{S}_{\mathrm{VCIL}}=\pi\left(\mathrm{L}_{\mathrm{T}}-\mathrm{L}_{\mathrm{N}}\right)$

Površina vrha letelice je:

$\mathrm{S}_{\mathrm{VV}}=\frac{\pi}{2} \mathrm{~L}_{\mathrm{N}}\left[1+\frac{1}{8 \mathrm{~L}_{\mathrm{N}}^{2}}\right]\left[1+\left(\frac{1}{3}+\frac{1}{50 \mathrm{~L}_{\mathrm{N}}^{2}}\right)\left(\frac{\mathrm{R}_{\mathrm{T}}}{\mathrm{R}}\right)\right]$,

pri čemu je:

$$
\mathrm{D}_{\mathrm{UM}}=1+\left(\frac{1}{3}+\frac{1}{50 \mathrm{~L}_{\mathrm{N}}^{2}}\right)\left(\frac{\mathrm{R}_{\mathrm{T}}}{\mathrm{R}}\right) \text {. }
$$

Prandtl je empirijsku formulu za turbulentni granični sloj korigovao zbog promene pritiska:

$C_{F T}=\frac{0.455}{\left(\log R_{e}\right)^{2.58}}\left(1+0.21 M_{\infty}^{2}\right)$

pri čemu su:

$R_{e}=\frac{V_{\infty} \cdot l}{v_{\infty}}-$ Rejnoldsov broj,

$\mathrm{V}_{\infty}=\mathrm{a}_{\propto} \mathrm{M}_{\infty}$ - brzina opstrujavanja ,

$\mathrm{l}=\mathrm{L}_{\mathrm{T}} \cdot \mathrm{d}_{\mathrm{REF}}-$ opstrujavana dužina $\mathrm{i}$

$\mathrm{d}_{\mathrm{REF}}$ - kalibar letelice.

Šlihting je pokazao veliku podudarnost Prandtlove empirijske formule i rezultata Van Driesta. Za vrednosti: $\mathrm{t}=15^{\circ} \mathrm{C}$, $\mu_{\propto}=1.7894 \cdot 10-5 \mathrm{~kg} / \mathrm{ms}$ i $\rho=1.225 \mathrm{~kg} / \mathrm{m}^{3}$ vrednost Rejnoldsovog broja iznosi: $\mathrm{R}_{\mathrm{e}}=23296.3 \cdot \mathrm{M}_{\propto} \cdot \mathrm{L}_{\mathrm{T}} \cdot \mathrm{d}_{\mathrm{REF}} \cdot$

\subsection{AERODINAMIČKI KOEFICIJENT OTPORA DNA PROJEKTILA}

Tačno određenje koeficijenta otpora dna letelice bio je predmet izučavanja mnogih analitičara. Kampan je posmatrao ravno dno na koje deluje bazni pritisak pri supersoničnim brzinama. Mahov broj određuje karakter graničnog sloja vazduha u okolini dna. Većina letelica ima turbulentni granični sloj u okolini dna. Odnos baznog pritiska $\mathrm{p}_{\mathrm{B}}$ i pritiska neporemećene struje $\mathrm{p}_{\propto}$ na osnovu teorijskih i empirijskih istraživanja, iznosi:

$$
\left[\frac{\mathrm{p}_{\mathrm{B}}}{\mathrm{p}_{\infty}}\right]=\left[1+0.09 \mathrm{M}_{\infty}^{2}\left(1-\mathrm{e}^{-\mathrm{L}_{\mathrm{CL}}}\right)\right]\left[1+\frac{1}{4} \mathrm{M}_{\infty}^{2}\left(1-\mathrm{d}_{\mathrm{B}}\right)\right],
$$

pri čemu je $\mathrm{L}_{\mathrm{CIL}}=\mathrm{L}_{\mathrm{T}}-\mathrm{L}_{\mathrm{N}}$.

Zbog uticaja Rejnoldsovog broja na karakter strujanja, ne postoji mogućnost potpunog poklapanja podataka efektivnog baznog pritiska dobijenog teorijskim i eksperimentalnim putem. Dobra korelacija postiže se za zadnji konus dužine do $\mathrm{L}_{\mathrm{BT}}=1.5 \mathrm{~d}$ i prečnika baze do $\mathrm{d}_{\mathrm{B}}=0,65 \mathrm{~d}$. Aerodinamički koeficijent otpora dna letelice dat je relacijom:

$$
\mathrm{C}_{\mathrm{XD}}=\frac{2 \mathrm{~d}_{\mathrm{B}}^{2}}{\chi \mathrm{M}_{\infty}^{2}}\left(1-\frac{\mathrm{p}_{\mathrm{B}}}{\mathrm{p}_{\infty}}\right)=1.4286 \cdot\left(1-\frac{\mathrm{p}_{\mathrm{B}}}{\mathrm{p}_{\infty}}\right) \frac{\mathrm{d}_{\mathrm{B}}^{2}}{\mathrm{M}_{\infty}^{2}} .
$$


Prethodna analiza odnosi se na projektile sa koničnim dnom, najveće debljine $d_{B}=1$, i pokazuje veliku sličnost sa eksperimentalnim.

\subsection{AERODINAMIČKI KOEFICIJENT OTPORA VODEĆEG PRSTENA}

Vodeći prsten klasičnih letelica uglavnom je lociran na zadnjem delu cilindričnog dela letelice, uz krivinu zadnjeg konusa. Za takav položaj vodećeg prstena otpor je manje vrednosti nego kod vodećih prstenova udaljenih od zadnjeg konusa. Promenom konfiguracije letelice uz veći broj eksperimenata mogao bi se smanjiti otpor vodećeg prstena (Roetzel, 2005). Na osnovu eksperimentalnih i teorijskih rezultata dobijena je poluempirijska analitička zavisnost promene aerodinamičkog koeficijenta otpora vodećeg prstena u funkciji Mahovog broja:

a) $\mathrm{C}_{\mathrm{XVP}}=\mathrm{M}_{\propto}{ }^{12.5}\left(\mathrm{~d}_{\mathrm{BND}}-1\right)$ za $\mathrm{M}<0.85$,

b) $\mathrm{C}_{\mathrm{XVP}}=0.76175 \mathrm{M}_{\propto}{ }^{12.62529}\left(\mathrm{~d}_{\mathrm{BND}}-1\right)$ za $0.85<M<0.95$,

c) $\mathrm{C}_{\mathrm{XVP}}=\left(0.21+\frac{0.28}{\mathrm{M}_{\infty}^{2}}\right)\left(\mathrm{d}_{\mathrm{BND}}-1\right)$ za $\mathrm{M}>0.95$.

\section{KONCEPCIJA PROGRAMSKOG REŠENJA}

Programsko rešenje AERODR metode za aerodinamički proračun napravljen je u programskim jezicima FORTRANU i PASCALU na personalnom računaru. Sastoji se od tri celine DATOTEKE (FILE):

1. Program AERODR- glavni program,

2. Datoteka ULAZ10 - ulazni podaci i

3. Datoteka IZLAZ10 - rezultati proračuna sa komentarom.

Program AERODR je organizovan tako da se proračun izvodi po celinama aerodinamičkog koeficijenta aksijalnog otpora. Naredbom READ učitavaju se polazni podaci sa datoteke ULAZ10. Potom se računaju aerodinamički koeficijenti otpora za različite vrednosti Mahovih brojeva. $\mathrm{Na}$ osnovu intervala nezavisne promenljive i broja tačaka definiše se korak proračuna. Koristeći FOR-petlju, redosledom za svaki korak računaju se komponente ukupnog aerodinamičkog koeficijenta $\mathrm{C}_{\mathrm{x}}(\mathrm{M})$ : $\mathrm{C}_{\mathrm{X} 1}(\mathrm{M}), \mathrm{C}_{\mathrm{XSF}}(\mathrm{M}), \mathrm{C}_{\mathrm{XVp}}(\mathrm{M}), \mathrm{C}_{\mathrm{X} 3}(\mathrm{M}), \mathrm{C}_{\mathrm{XB}}(\mathrm{M})$, i $\mathrm{P}_{\mathrm{B}} / \mathrm{P}_{1}(\mathrm{M})$. Na kraju proračuna komponenata sabiraju se i proračunavaju se ukupni aerodinamički koeficijenti za različite Mahove brojeve.

Datoteka ULAZ10 sadrži polazne podatke odvojene zarezom i grupisane u tri reda:

- prvi red sadrži broj projektila za koji se vrši proračun,

- drugi red sadrži karakteristike letelice i

- treći red sadrži vrstu graničnog sloja oko letelice.

Datoteka IZLAZ10 se kreira u toku izvršenja programa u nju se smeštaju dobijene informacije naredbom WRITE programa. To su rezultati aerodinamičkog proračuna. Strukturisani su tako da se na početku daju polazni podaci potom tabelarni rezultati za ukupni aerodinamički koeficijent aksijalne sile i njene komponente $\mathrm{u}$ funkciji zadatih Mahovih brojeva.

Ovako koncipirano programsko rešenje je univerzalno i može se upotrebiti za sve vrste klasičnih žiroskopski stabilisanih letelica pri osnosimetričnom opstrujavanju (Tablice gađanja za haubicu $122 \mathrm{~mm}$ ). Za aerodinamički proračun novog, željenog žirostabilisane letelice neophodno je datoteku ULAZ10 modifikovati ili kreirati novu sa polaznim podacima odabrane letelice.

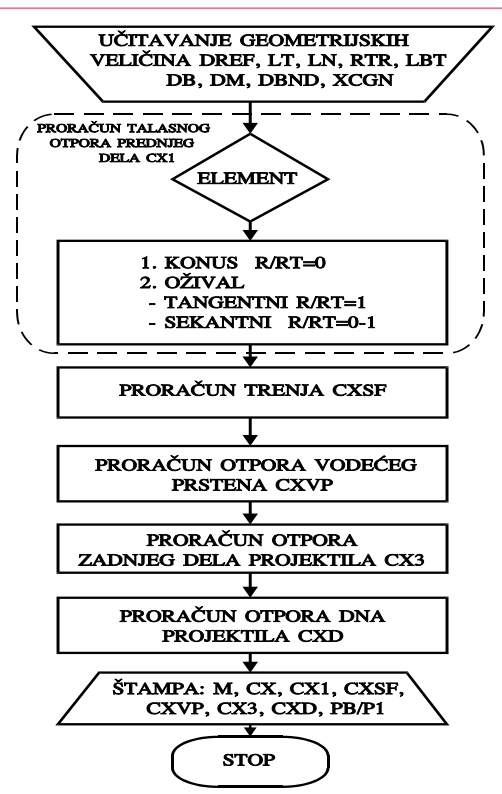

Slika 4 .

\subsection{REZULTATI AERODINAMIČKOG PRORAČUNA}

U tabeli 2. Prikazani su rezultati proračuna promene pritiska iza dna letelice, aerodinamičkog koeficijenta Cx i njegovih komponenata u funkciji Mahovog broja. Realizovane su simulacije:

1. Simulacija 1: Datoteka polazni podaci „ULAZ10” $\mathrm{DREF}=122 \mathrm{~mm}, \mathrm{LT}=5.049, \mathrm{LN}=2.582, \mathrm{RTR}=0.76$, $\mathrm{LBT}=0.787, \mathrm{DB}=0.934, \mathrm{DM}=0.062, \mathrm{DBND}=1.022$, $\mathrm{XCGN}=3.15 \mathrm{BLC}=2$.

2. Simulacija 2: Datoteka polazni podaci „ULAZ10” $\mathrm{DREF}=122 \mathrm{~mm}, \mathrm{LT}=4.891, \mathrm{LN}=2.582, \mathrm{RTR}=0.76$, $\mathrm{LBT}=0.387, \mathrm{DB}=0.87, \mathrm{DM}=0.062, \mathrm{DBND}=1.022$, $\mathrm{XCGN}=3.15 \mathrm{BLC}=2$.

Datoteka rezultati proračuna „IZLAZ10” za simulacija 1.

U tabeli 2. dat je uporedni prikaz aksijalnog aerodinamičkog koeficijenta za letelice $122 \mathrm{~mm}$ i $\mathrm{M}=0.5$,

\begin{tabular}{|c|c|c|c|c|c|c|c|}
\hline CX & $\mathrm{CX}$ & $\mathrm{CX}$ & SF & CXVP & CX3 & CXD & $\mathrm{PB} / \mathrm{P} 1$ \\
\hline .500 & .172 & .000 & .051 & .000 & .000 & .121 & .976 \\
\hline .600 & .174 & .000 & .050 & .000 & .000 & .124 & .964 \\
\hline .700 & .177 & .000 & .048 & .000 & .000 & .129 & .949 \\
\hline .800 & .181 & .000 & .046 & .001 & .000 & .133 & .932 \\
\hline .850 & .183 & .000 & .046 & .002 & .000 & .135 & .922 \\
\hline .900 & .189 & .002 & .045 & .004 & .000 & .137 & .911 \\
\hline .925 & .208 & .017 & .045 & .006 & .001 & .138 & .905 \\
\hline .950 & .227 & .032 & .045 & .009 & .002 & .139 & .899 \\
\hline .975 & .246 & .046 & .044 & .011 & .005 & .140 & .893 \\
\hline 1.000 & .300 & .059 & .044 & .011 & .010 & .177 & .858 \\
\hline 1.100 & .366 & .133 & .043 & .010 & .006 & .174 & .831 \\
\hline 1.200 & .362 & .127 & .042 & .009 & .012 & .172 & .802 \\
\hline 1.300 & .349 & .121 & .041 & .008 & .011 & .168 & .772 \\
\hline 1.400 & .332 & .110 & .040 & .008 & .011 & .165 & .741 \\
\hline 1.500 & .329 & .112 & .039 & .007 & .010 & .161 & .710 \\
\hline 1.600 & .320 & .109 & .038 & .007 & .009 & .157 & .678 \\
\hline 1.700 & .311 & .106 & .037 & .007 & .009 & .152 & .647 \\
\hline 1.800 & .303 & .104 & .036 & .007 & .008 & .148 & .617 \\
\hline 2.000 & .287 & .100 & .035 & .006 & .008 & .138 & .557 \\
\hline 2.200 & .271 & .097 & .033 & .006 & .007 & .128 & .502 \\
\hline 2.500 & .250 & .093 & .031 & .006 & .006 & .114 & .429 \\
\hline 3.000 & .220 & .088 & .028 & .005 & .005 & .093 & .332 \\
\hline 3.500 & .195 & .085 & .026 & .005 & .005 & .075 & .262 \\
\hline 4.000 & .176 & .082 & .024 & .005 & .004 & .061 & .212 \\
\hline
\end{tabular}




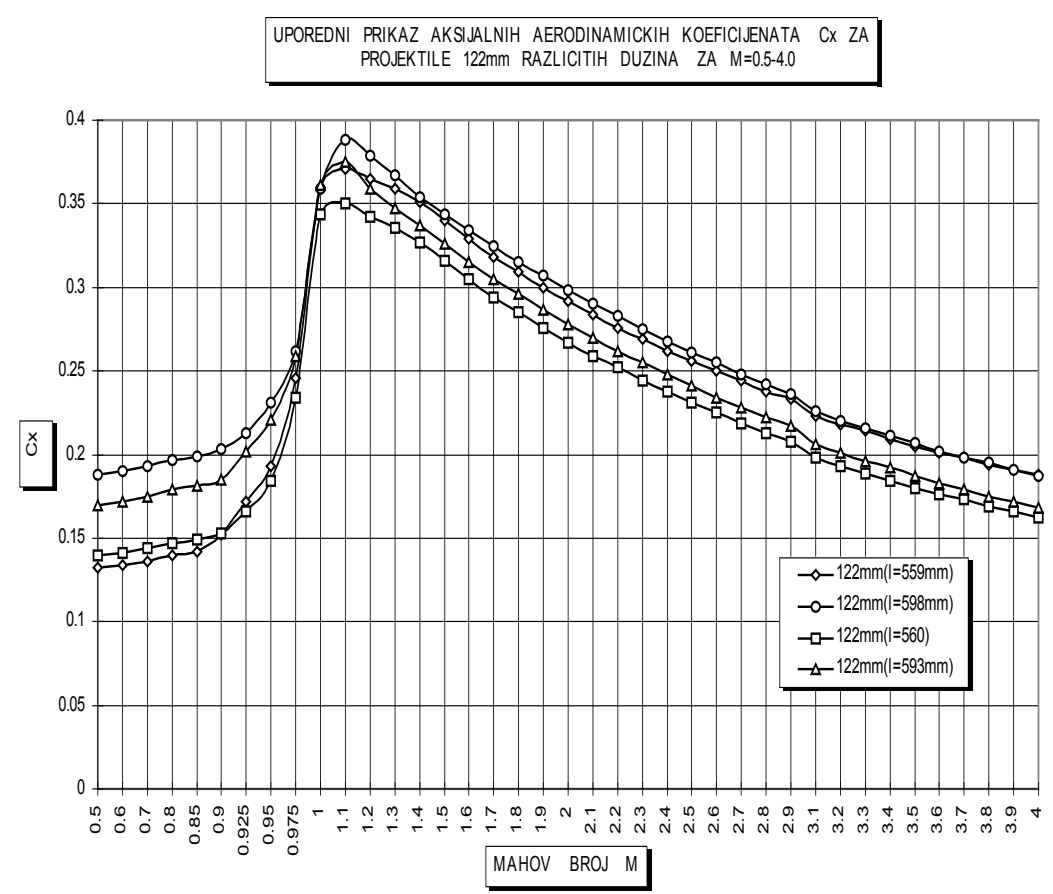

Slika 5. Uporedni prikaz akcijalnih aerodinamičkih koeficijenata Cx za projektile $122 \mathrm{~mm}$ različ̌itih dužina $(559 \mathrm{~mm}, 598 \mathrm{~mm}$, $560 \mathrm{~mm}$ i $593 \mathrm{~mm}$ ) za interval $\mathrm{M}=0,5-4,0$.

Na slici 5. data je grafička interpretacija realizovanih simulacija za letelice kalibra $122 \mathrm{~mm}$ različitih dužina $(559 \mathrm{~mm}$, $598 \mathrm{~mm}, 560 \mathrm{~mm}$ i $593 \mathrm{~mm}$ ) za interval brzine leta u intervalu $\mathrm{M}=0,5-4,0$.

\section{REZIME}

U radu je prikazan postupak proračuna aerodinamičkih koeficijenata aksijalne sile osnosimetrične letelice. Prikazani model poluempirijskog proračuna omogućio je dobijanje realnih vrednosti aksijalnih koeficijenata $\mathrm{Cx}$, komponenti koeficijenata i derivativa za sve strujne režime (podzvučno, okolozvučno i nadzvučno opstrujavanje). Proračun je izvršen za klasičan osnosimetrični model letelice za osnosimetrično opstrujavanje (bez napadnog ugla). Dobijeni rezultati imaju praktičnu primenu za određivanje vrednosti aerodinamičkih koeficijenata osnosimetričnih letelica, na osnovu poznate geometrije.

Izvršena je korekcija teorijskog modela (McCoy, 1999) i smanjena odstupanja do pet procenata. Izvršena je detaljna analiza rezultata proračunskih istraživanja. Dobijeni rezultati $\mathrm{Cx}(\mathrm{M})$ ne prelaze zadanu teorijsku prednost 0,4 . Izvršena je analiza, dobijenih proračunskih vrednosti koeficijenata za model letelice $122 \mathrm{~mm}$ (dužina: $559 \mathrm{~mm}, 598 \mathrm{~mm}, 560 \mathrm{~mm}$ i $593 \mathrm{~mm}$ ) za interval $\mathrm{M}=0,5-4,0)$. Dokazano je da aerodinamički koeficijent aksijalne sile predstavlja jedan od najznačajnijih koeficijenata koji definiše aerodinamičku silu i utiče na elemente putanje letelice u području supersoničnih brzina, karakterističnih za ovu vrstu letelice. Maksimalna vrednost $\mathrm{Cx}$ se javlja u intervalu $\mathrm{M}=1,1$.
Rezultati dobijeni proračunom u skladu su sa postavljenim pretpostavkama i u okviru očekivanih vrednosti. Razmatrani model proračuna može se koristiti u svim budućim proračunima navedene klase letelica.

\section{LITERATURA}

McCoy, R.L. (1999). Modern exterior ballistics: The launch and flight dynamics of symmetric projectiles. Atglen, PA: Schiffer Pub.

Regodić, D. (2003). Zbirka rešenih zadataka iz spoljne balistike. Beograd: UŠIO.

Regodić, D. (2006). Spoljna balistika. Beograd: Vojna akademija.

Regodić, D., Jevremović, A., \& Jerković, D. (2013). The prediction of axial aerodynamic coefficient reduction using base bleed. Aerospace Science and Technology, 31(1), 24-29. DOI: 10.1016/j.ast.2013.09.001

Roetzel, W. (2005). Analytical calculation of trajectories using a power law for the drag coefficient variation with mach number. Second International Conference of Computational Ballistics. Southampton: WIT Press.

Ul-Haque, A., \& Umar, F. (2005). Study of asymmetric vortical flow on forebody at high angle of attack. Second International Conference of Computational Ballistics. Wessex Institute of Technology, Southampton: WIT Press. 